\title{
Ba-DOPED ZnO MATERIALS: A DFT SIMULATION TO INVESTIGATE THE DOPING EFFECT ON FERROELECTRICITY
}

\author{
Luis H. da S. Lacerda e Sergio R. de Lazaro* \\ Departamento de Química, Universidade Estadual de Ponta Grossa, 84030-900 Ponta Grossa - PR, Brasil
}

Recebido em 30/07/2015; aceito em 03/11/2015; publicado na web em 18/02/2015

\begin{abstract}
$\mathrm{ZnO}$ is a semiconductor material largely employed in the development of several electronic and optical devices due to its unique electronic, optical, piezo-, ferroelectric and structural properties. This study evaluates the properties of Ba-doped wurtzite- $\mathrm{ZnO}$ using quantum mechanical simulations based on the Density Functional Theory (DFT) allied to hybrid functional B3LYP. The Badoping caused increase in lattice parameters and slight distortions at the unit cell angle in a wurtzite structure. In addition, the doping process presented decrease in the band-gap $\left(\mathrm{E}_{\mathrm{g}}\right)$ at low percentages suggesting band-gap engineering. For low doping amounts, the wavelength characteristic was observed in the visible range; whereas, for middle and high doping amounts, the wavelength belongs to the Ultraviolet range. The $\mathrm{Ba}$ atoms also influence the ferroelectric property, which is improved linearly with the doping amount, except for doping at $100 \%$ or wurtzite- $\mathrm{BaO}$. The ferroelectric results indicate the $\mathrm{ZnO}: \mathrm{Ba}$ is an strong option to replace perovskite materials in ferroelectric and flash-type memory devices.
\end{abstract}

Keywords: electronic structure; semiconductors; theoretical; $\mathrm{ZnO}$ :Ba; doping; ferroelectricity.

\section{INTRODUCTION}

Theoretical methods based on quantum mechanical simulations are an important tool to evaluate material properties, mainly at the molecular level. Studies based on these methods are performance to evaluate the electronic, optical, structural, pyro-, piezo- and ferroelectric properties. Such properties are intrinsically dependent on composition, atomic organization and chemical bonds, once these factors change the charge density on materials. One example is semiconductor materials, which are largely employed to develop electronic, optical devices, piezoelectric and memory devices. ${ }^{1-12}$ Actually, such devices are constructed using perovskite materials that have wide band gap allied to electronic, optical, piezo-, pyro-, ferroelectric and ferromagnetic properties. ${ }^{13-18}$ However, the application of these materials is difficult and significantly delayed due to hard adjustment between the semiconductor structure lattice parameters and the substrate, mainly on Si substrates. ${ }^{13,19-21}$ Besides, the perovskite nanostructure properties can be drastically different from its bulk properties; ${ }^{6}$ thus, simple oxide semiconductors are presented as a viable alternative to replace the perovskite materials. ${ }^{3,6,21,22}$

For many years, the wurtzite zinc oxide $(\mathrm{ZnO})$ has attracted interest due to its unique electronic, optical and piezoelectric properties. Allied to these properties, the $\mathrm{ZnO}$ material has a low cost production due to its availability ${ }^{23,24}$ and it is found in three crystalline structures: blend, rock-salt and wurtzite. Such structures are made up by two zinc atoms and two oxygen atoms arranged in a hexagonal unit cell of spatial group $\mathrm{P}_{3} \mathrm{mc}$ (186). The $\mathrm{ZnO}$ is an n-type semiconductor of wide band gap of $3.37 \mathrm{eV}^{13-15,25,26}$ and shows piezo-, pyro- and ferroelectric properties due to the charge dipoles in the structure. ${ }^{23-25,27,28}$ However, the use of $\mathrm{ZnO}$ in a wide range of applications would not be possible without the doping process, which can be used to change drastically the material properties keeping the crystalline structure. The incorporation of group I and II elements improves the ferroelectric properties and enables the band-gap engineering for this material $;^{29}$ whereas, group III provides the transparent-conducting-oxide property. ${ }^{30}$ Transition metals make a multiferroic semiconductor. In particular, Ba-doped $\mathrm{ZnO}$ material has not been largely studied, since just $\mathrm{ZnO} / \mathrm{BaTiO}_{3}$ heterojunction ${ }^{31-34}$ and $\mathrm{BaO} / \mathrm{ZnO}$ interfaces ${ }^{35}$ have been recently investigated. The most common atoms inserting in the $\mathrm{ZnO}$ structure are $\mathrm{N},{ }^{36,37} \mathrm{Pd},{ }^{37} \mathrm{Mg},{ }^{38} \mathrm{Gd}^{39}$ atoms and lanthanide metals. ${ }^{40}$

Nowadays, theoretical and experimental studies on doped $\mathrm{ZnO}$ materials have been performed to propose materials which might be viable alternatives to replace the perovskite materials. ${ }^{6,9,10,12,19,20,29,41-43}$ Thus, the aim of this study was to perform computational simulations based on DFT/B3LYP to evaluate the effect of low and large Ba doping on $\mathrm{ZnO}$ due to its great potential to replace perovskite-type materials in ferroelectric and opto-electronic devices.

\section{COMPUTATIONAL METHODOLOGY}

The simulation for $\mathrm{ZnO}$ material was performed based on a wurtzite structure in accordance to Özgür and co-workers. ${ }^{23} \mathrm{~A}$ Badoped model $(\mathrm{Ba}: \mathrm{ZnO})$ was developed from unit cell expansion in the direction of axes a, b and c, resulting at 12.5-100\% doping (Figure 1 and Table 1). For all models, the TZVP ${ }^{44}$ basis set was employed to describe the $\mathrm{Zn}$ and $\mathrm{O}$ atoms; whereas, the $\mathrm{Ba}$ atoms were described by Zagorac ${ }^{45}$ basis set employing the HAYWSC ${ }^{46}$ pseudopotential.

The calculation level applied was based on the Density Functional Theory (DFT) at set B3LYP hybrid functional; ${ }^{47-50}$ SCF convergence was truncated in $10^{-8}$ Hartree and Mohnkhost-Pach ${ }^{51,52}$ method defined as $8 \times 8$ using CRYSTAL0 $9^{53,54}$ software. Vibrational calculations were also performed using the optimized results for all models to evaluation of thermodynamic stability at room temperature $(298.5 \mathrm{~K})$ and $1 \mathrm{~atm}$. The theoretical results discussed were Density of States (DOS) Projections and Band Structure analysis. The XCrysden ${ }^{55,56}$ Software was used for the structural analysis. Ubuntu Linux platforms made up by seven quad-core AMD computers with $32 \mathrm{~GB}$ of RAM and data storage capability of $3.5 \mathrm{~TB}$ were used in all simulations. 
Table 1. Description of the unit cells used for simulating the Ba-doping on $\mathrm{ZnO}$ material

\begin{tabular}{ccc}
\hline Doped amount $(\%)$ & Unit cell expansion & Zn atoms replaced \\
\hline 0 & $2 \times 2 \times 2$ & 0 \\
6.25 & $2 \times 2 \times 2$ & 1 \\
12.5 & $2 \times 2 \times 1$ & 1 \\
25.0 & $2 \times 2 \times 1$ & 2 \\
37.5 & $2 \times 2 \times 1$ & 3 \\
50.0 & $2 \times 2 \times 1$ & 4 \\
62.5 & $2 \times 2 \times 1$ & 5 \\
75.0 & $2 \times 2 \times 1$ & 6 \\
87.5 & $2 \times 2 \times 1$ & 7 \\
100 & $2 \times 2 \times 1$ & 8 \\
\hline
\end{tabular}

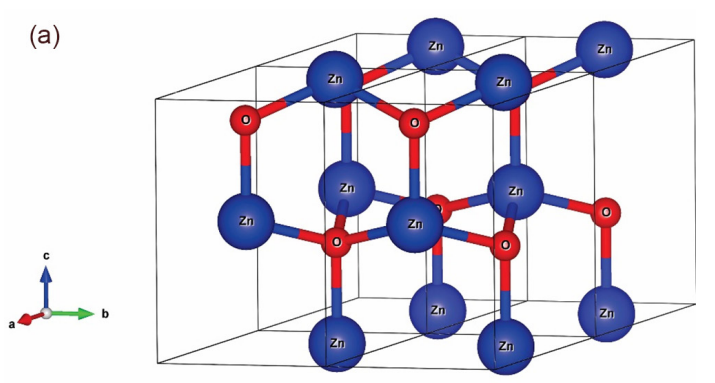

(b)

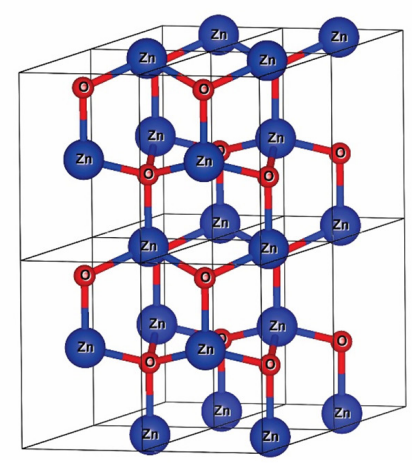

Figure 1. Crystalline structures for Ba:ZnO materials. a) $2 \times 2 x 1$ wurtzite supercell. b) $2 \times 2 \times 2$ wurtzite supercell

\section{RESULTS AND DISCUSSION}

$\mathbf{Z n}_{(1-\mathbf{x})} \mathbf{B a}_{\mathbf{x}} \mathrm{O}$

\section{Structural Properties}

In 1921, Lars Vegard investigated the amount of doping effect on the crystalline structure of ionic structures through X-Ray diffraction (XRD) showing an empirical rule, which was called "Vegard's Law". This rule is a linear relationship between lattice parameters and impurity amount and it was improved by Barret (1952), Hume-Rothery and partners (1969) and Benett (1979); furthermore, studies have shown that the crystalline structure is influenced by atomic size, volume and number of electron ratio, the doping effects on the Brillouin Zone and the electrochemical differences between the elements. According to Vegard's law, the linear behaviour is associated to the doping process, which causes lattice parameters reduction and exhibits an attractive character between atoms. On the other hand, the nonlinear increase in lattice parameters presents a repulsive character between atoms.
Therefore, an ideal behaviour for a solid solution is characterized by a linear increase in lattice parameters regarding the doping amount in a crystalline structure, indicating the possibility of synthesis. ${ }^{57,58}$

Theoretical results for $\mathrm{ZnO}$ lattice parameters and band-gap are shown in the Table $1 \mathrm{~S}$ in Supplementary Material (SM). It is observed that lattice parameters are in good agreement with X-Ray Diffraction and other theoretical results; whereas, the band gap is in accordance with the expected value of $3.37 \mathrm{eV} \cdot{ }^{13-15,25,26}$

Structural results for $\mathrm{Ba}: \mathrm{ZnO}$ models (Table 2) are discussed through lattice parameters. For wurtzite structure, $a=b \neq c$ lattice parameters and $\alpha=\beta=90^{\circ}$ and $\gamma=120^{\circ}$ angles; however, the Badoping at $6.25 \%, 12.5 \%, 25 \%, 37.5 \%, 62.5 \%, 75 \%$ and $87.5 \%$ shows a crystalline phase distortion, once the $\mathrm{a}$ and $\mathrm{b}$ lattice parameters and $\beta$ and $\gamma$ angles presented deviation from the expected values for a wurtzite structure. Nevertheless, the Brillouin Zone and tetragonality factor (c/a) were slight modified after the doping process keeping wurtzite-ZnO structure. The lattice parameters variation is caused by bond length increase after the doping process. In the $\mathrm{ZnO}$ material, the $\mathrm{Zn}-\mathrm{O}$ bond length is $1.980 \AA$; whereas, in the Ba-doped models there is a tetrahedron distortion evidenced by deviation in the $\mathrm{Zn}-\mathrm{O}$ bond lengths. In particular, the Ba-doped models from $6.25 \%$ to $37.5 \%$, the $\mathrm{Zn}-\mathrm{O}$ and $\mathrm{Ba}-\mathrm{O}$ bond lengths were $1.941 \AA$ and $2.016 \AA$, respectively; whereas, for percentages from $62.5 \%$ to $87.5 \%$, such bond lengths were calculated between $2.003 \AA$ and $2.203 \AA$, respectively. For Ba-doped models at $50 \%$ and $100 \%$, the $\mathrm{Zn}-\mathrm{O}$ and $\mathrm{Ba}-\mathrm{O}$ bond lengths were calculated at $1.980 \AA$ and $2.497 \AA$, respectively. For the doped model at $62.5 \%$, c lattice parameter is not linearly affected by $\mathrm{Ba}$ atoms insertion in crystalline structure. Such deviation from wurtzite- $\mathrm{ZnO}$ crystalline structure was caused because of unequal distribution of the $\mathrm{Ba}$ atoms amount in relation to tetrahedron sites number; consequently, the $\mathrm{Ba}$ atoms in excess are concentred in a region along of $\mathrm{ZnO}$ unit cell as consequence of random distribution in the occupation of tetrahedron sites. Although, the wurtzite crystalline phase distortion occurs, there is a linear increase of lattice parameters in relation to Ba-doping in according to Vegard's law. Thus, the Ba atoms insertion in the wurtzite- $\mathrm{ZnO}$ structure can be characterized as an ideal behaviour indicating the possible formation of solid solution. In Thermodynamic Stability Evaluation Section, we present an theoretical investigation from Gibbs Free Energy stability for Ba:ZnO materials.

\section{Electronic Property}

The electronic properties of $\mathrm{ZnO}$ and $\mathrm{Ba}: \mathrm{ZnO}$ materials were evaluated through the projected Density of States (DOS), Figure 1S. Such DOS results are evaluated from last five energy bands of the Valence Band (VB) and first five energy bands of the Conduction Band $(\mathrm{CB})$ featuring the band-gap region $\left(\mathrm{E}_{\mathrm{g}}\right)$. In the $\mathrm{ZnO}$ model, the $\mathrm{O}$ atoms largely contributed to composition on all $\mathrm{VB}$ and for higher energy levels of $\mathrm{CB}$. The VB energy levels were predominantly made for $2 p$ orbitals; whereas, the CB energy levels were composed of $2 \mathrm{p}$ and $3 \mathrm{~s}$ orbitals. $\mathrm{Zn}$ atoms showed low contribution by $3 \mathrm{~d}$ and $4 \mathrm{~s}$ orbitals at the top of $\mathrm{VB}$; whereas, doping process shows low impact on the $\mathrm{O}$ and $\mathrm{Zn}$ orbitals contributions in $\mathrm{VB}$ and $\mathrm{CB}$. Barium atoms were predominant at the top of the VB through 5p orbitals in large proportion; while, $3 \mathrm{~d}$ orbitals were calculated as low contribution. Regarding $\mathrm{CB}$, the $\mathrm{Ba}$ atoms contribution was calculated mainly through $3 \mathrm{~d}$ and $5 \mathrm{~s}$ orbitals. The insertion of $\mathrm{Ba}$ atoms shows a strong effect on the energy of the top of the VB and bottom of CB as better discussed on Optical Properties Section. Besides, doping process also reduces the contribution of the oxygen atom on $\mathrm{CB}$ causing modification of $E_{\mathrm{g}}$. Such modification is based on change in the VB and $\mathrm{CB}$ energy levels; for $\mathrm{E}_{\mathrm{g}}$ of $\mathrm{ZnO}$ material the energy levels for top of $\mathrm{VB}$ and bottom of $\mathrm{CB}$ are observed from -10 to $-6 \mathrm{eV}$ and 
Table 2. Lattice parameters (in $\AA$ ), unit cell angles (in degrees) and Tetragonal factor (c/a) for Ba: $\mathrm{ZnO}$ models

\begin{tabular}{|c|c|c|c|c|c|c|c|}
\hline Doping amount (\%) & $\mathrm{a}$ & b & c & $\alpha$ & $\beta$ & $\gamma$ & $a / c$ \\
\hline 0.0 & 3.266 & 3.266 & 5.279 & 90 & 90 & 120 & 1.616 \\
\hline 6.12 & 3.325 & 3.338 & 5.324 & 90 & 90.118 & 120.121 & 1.601 \\
\hline 12.5 & 3.364 & 3.399 & 5.464 & 90 & 90.060 & 120.346 & 1.624 \\
\hline 25.0 & 3.503 & 3.443 & 5.691 & 90 & 92.168 & 119.429 & 1.653 \\
\hline 37.5 & 3.633 & 3.630 & 5.878 & 90 & 89.834 & 119.967 & 1.619 \\
\hline 50.0 & 3.754 & 3.754 & 6.104 & 90 & 90 & 120 & 1.626 \\
\hline 62.5 & 3.884 & 3.980 & 5.665 & 90.670 & 90 & 119.203 & 1.441 \\
\hline 75.0 & 4.101 & 3.983 & 6.218 & 90 & 90.438 & 119.051 & 1.561 \\
\hline 87.5 & 4.166 & 4.180 & 6.421 & 89.803 & 90 & 119.891 & 1.542 \\
\hline 100 & 4.273 & 4.273 & 6.652 & 90 & 90 & 120 & 1.557 \\
\hline
\end{tabular}

-2 to $11 \mathrm{eV}$, respectively; whereas, for doped materials such bands are calculated from -6 to $-5 \mathrm{eV}$ and -2 to $2 \mathrm{eV}$, respectively. Then, from same number of energy levels analyzed was noted an energetic equiparation of these electronic levels or an electronic degeneration (see SM - Figure 1S and Figure 2S).

\section{Optical Property}

The optical property of a solid is defined as an interaction between the solid and electromagnetic radiation. Semiconductor materials interact only with electromagnetic energy equal to or higher than $\mathrm{E}_{\mathrm{g}} \cdot{ }^{59,60}$ Therefore, the presence of $\mathrm{Ba}$ atoms in the crystalline structure causes changes in the band structure (Figure 2S); mainly, through variation in $\mathrm{E}_{\mathrm{g}}$ calculated to $6.12 \%, 12.5 \%, 25 \%, 37.5 \%, 50 \%$ and $100 \%$ models, all with indirect $\mathrm{E}_{\mathrm{g}}$ (Figure $2 \mathrm{~S}$ ). On the other hand, the direct $\mathrm{E}_{\mathrm{g}}$ (Figure $2 \mathrm{~S}$ ) calculated to $0 \%, 62.5 \%, 75 \%$ and $87.5 \%$ models show wavelengths associated from Middle Ultraviolet to UltravioletVisible (UV-Vis), Table 2S in SM. We evaluate the optical property through $\mathrm{E}_{\mathrm{g}}$ values (Table $2 \mathrm{~S}-\mathrm{SM}$ ) showing that a non-linear $\mathrm{E}_{\mathrm{g}}$ plot in relation to $\mathrm{Ba}$ doping. To discuss such non-linear behaviour of $\mathrm{E}_{\mathrm{g}}$, all results for $\mathrm{Ba}: \mathrm{ZnO}\left(\mathrm{E}_{\text {gmodel }}\right)$ were referenced to the $\mathrm{ZnO}$ material $\left(\mathrm{E}_{\text {gpure }}\right)$ as shown in Equation 1 and plotted in Figure 2.

$$
\Delta E_{g}=E_{g_{\text {model }}}-E_{g_{\text {pure }}}
$$

According to Figure 2, only the doped models from $6.35 \%$ to

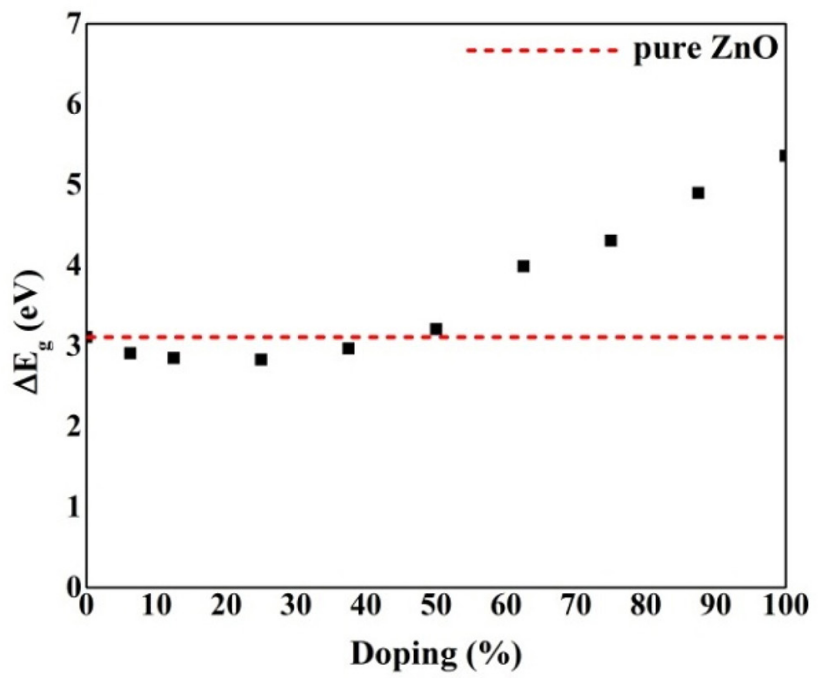

Figure 2. Theoretical results in according to $\mathrm{ZnO}$ band gap to Ba-dopant amount
$37.5 \%$ have satisfactory results for $\mathrm{E}_{\mathrm{g}}$ decrease in relation to $\mathrm{ZnO}$. For the Ba-doped models above $50 \%$, the results show the increase of $\mathrm{E}_{\mathrm{g}}$. To visualize better such changes $\left(\Delta \mathrm{E}_{\mathrm{g}}-\right.$ Figure 3$)$, the top of $\mathrm{VB}$ and bottom of $\mathrm{CB}$ energy levels were referenced to $\mathrm{ZnO}$ (Figure 3 ). These results indicate an increase between $2.2 \mathrm{eV}$ and $4.4 \mathrm{eV}$ in energy at the top of VB and bottom of CB, respectively. Therefore, the energy presented by $6 \mathrm{~s}, 6 \mathrm{p}$ and $3 \mathrm{~d}$ atomic orbitals in doped materials were higher than $\mathrm{ZnO}$ (see SM, Figure 1S).

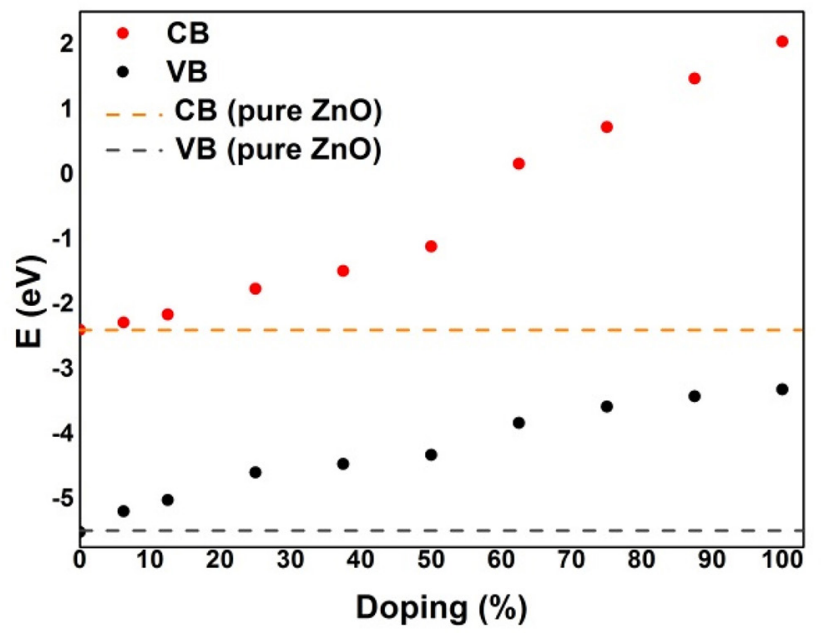

Figure 3. Energy levels calculated from DFT/B3LYP at the top of Valence Band (VB) and the bottom of Conduction Band (CB) according to Ba-doping amount and referenced to $\mathrm{ZnO}$

\section{Ferroelectric Property}

In a ferroelectric material, the direction of charge polarization can be reversed by applying an external electrical field, which is very important to the charge storage property. In order to better understand such property, the solid state theory developed the dielectric constants $(\varepsilon)$ and polarizability $(\alpha)$ concepts. In general, the dielectric constant determines the charge storage capacity; whereas, the polarizability describes how much a material is polarizable under an electrical field. Once these values increase, the material has a high ferroelectric property; however, as $\varepsilon$ as $\alpha$ are dependents on the tensor matrix, which is directed similarly to Cartesian coordinates system. ${ }^{59}$ The $\varepsilon$ and $\alpha$ results for $\mathrm{ZnO}$ and $\mathrm{Ba}: \mathrm{ZnO}$ models are presented in the Table 3. It is observed that the doping process improves the dielectric constants for Ba-doped models from $6.12 \%$ to $87.5 \%$ because theoretically there is an increase in all tensor matrix components in relation to $\mathrm{ZnO}$. The highest value for dielectric constant was simulated for Ba-doped 
Table 3. Polarizability $(\alpha)$ and dielectric constants $(\varepsilon)$ for $\mathrm{ZnO}$ and $\mathrm{Ba}: \mathrm{ZnO}$ models

\begin{tabular}{|c|c|c|c|c|c|c|}
\hline \multirow{2}{*}{ Doping (\%) } & \multicolumn{3}{|c|}{$\alpha$} & \multicolumn{3}{|c|}{$\varepsilon$} \\
\hline & $\mathrm{xx}$ & yy & $\mathrm{zZ}$ & $\mathrm{xx}$ & yy & $\mathrm{zz}$ \\
\hline 0.0 & 61.2868 & - & 61.8148 & 3.3273 & - & 3.3521 \\
\hline 6.12 & 69.4224 & 69.4229 & 70.9920 & 3.5325 & 3.5326 & 3.5806 \\
\hline 12.5 & 70.9469 & 70.9272 & 73.1146 & 3.5817 & 3.5817 & 3.6605 \\
\hline 25.0 & 84.1901 & 85.1401 & 86.836 & 3.6372 & 3.6670 & 3.7201 \\
\hline 37.5 & 96.1809 & 96.1822 & 96.3698 & 3.6679 & 3.6679 & 3.6731 \\
\hline 50.0 & 106.2047 & - & 102.4798 & 3.6549 & - & 3.5618 \\
\hline 62.5 & 208.6845 & 424.2743 & 114.8460 & 6.1233 & 11.4160 & 3.8195 \\
\hline 75.0 & 661.0670 & 110.7885 & 706.4301 & 14.9922 & 3.3450 & 15.9523 \\
\hline 87.5 & 111.7494 & 111.7511 & 1220.6789 & 3.1490 & 3.1490 & 24.4739 \\
\hline 100 & 107.8717 & - & 117.3194 & 2.8566 & - & 3.0770 \\
\hline
\end{tabular}

model at $87.5 \%$. Regarding doping at $100 \%$, a decrease in $\varepsilon$ for three components in relation to $\mathrm{ZnO}$ was observed.

The increase observed in the $\varepsilon$ and $\alpha$ results in relation to $\mathrm{Ba}-$ doping can be understood due to the tetrahedron distortion in the wurtzite structure. Such distortions are evidenced by changes in the bond length after the doping process (see Structure Properties Section) and they are responsible for the increase of the dielectric constants and polarizability. Another point is associated to the atoms which were distributed randomly in crystalline structure causing a symmetry lower than $\mathrm{ZnO}$; consequently, the electronic density was disorderly distributed and provided ferroelectric and dielectric properties higher than those in the $\mathrm{ZnO}$.

Recently, the perovskite-type materials have been largely employed in the development of ferroelectric memories and charge storage devices because they present high values for polarizability and dielectric constants. ${ }^{13-18}$ However, the production process of such devices is hampered due to the difficulty of interface between perovskite-type structure and $\mathrm{Si}$ substrate. ${ }^{13,19-21} \mathrm{ZnO}$ and Ba-doped $\mathrm{ZnO}$ can be easily adjusted to this substrate because of similar structures; such as, tetrahedral sites, hexagonal group and lattice parameters. Based on our theoretical results, the $\mathrm{ZnO}: \mathrm{Ba}$ at $87.5 \%$ is a potential alternative to replace perovskite-type materials in ferroelectric devices, for instance, Random Access Memory (RAM), flash-type memories or flash-drives; nevertheless, the structural instability forecasted can be a great challenge to synthesis methods.

\section{Thermodynamic Stability Evaluation}

Structure properties results indicated that the $\mathrm{Ba}: \mathrm{ZnO}$ materials have showed an ideal character according to Vegard's law. Thus, it is expected that such materials can be obtained by experimental techniques, once the crystalline structure are linearly changed with the dopant amount. However, in literature some manuscripts focused on $\mathrm{Ba}: \mathrm{ZnO}$ materials ${ }^{29,35,61-64}$ report that the solubility of $\mathrm{Ba}$ atoms is limited at $5 \% \mathrm{~mol}$ in wurtzite- $\mathrm{ZnO}$ structure. These manuscripts also present temperature influence on Ba solubility, which is slightly increased in high temperatures. Nevertheless, such Ba solubility decrease with the temperatures reduction and there is segregation of $\mathrm{Ba}$ atoms inside wurtzite- $\mathrm{ZnO}$ structure. Assuming that the Vegard's law prevision is not enough to determines the stability of $\mathrm{Ba}: \mathrm{ZnO}$ materials. Therefore, from vibrational calculations based on DFT/ B3LYP we calculate the mixing Gibbs Free Energy $\left(\Delta \mathrm{G}_{\text {mix }}-\right.$ Eq. 2$)$ and Gibbs Free Energy in relation to pure $\mathrm{ZnO}(\Delta \Delta \mathrm{G}-$ Eq. 3).

$$
\begin{gathered}
\Delta G_{m i x}=G_{\text {products }}-\left(\Sigma G_{Z n O}+x G_{B a O}\right) \\
\Delta \Delta G=\Delta G_{m i x}-\Delta G_{Z n O}
\end{gathered}
$$

The positive value for $\Delta \Delta \mathrm{G}$ of these models indicates that these models are not favorable to be obtained through experimental techniques. Then, the obtained results for Thermodynamic Stability of Ba-doped and pure $\mathrm{ZnO}$ (Table 4) show instability for $37.5 \%, 50 \%$ and $62.5 \%$ doping at room conditions from positive $\Delta \Delta \mathrm{G}$ values calculated, whereas; $12.5 \%, 25.0 \%, 75 \%$ and $87 \%$ doping indicate a stability at room conditions. For many years, experimental techniques showed a Ba solubility in the $\mathrm{ZnO}$ structure limited at $2.5 \% \mathrm{~mol}$, such techniques were based on traditional techniques, such as, precipitation and ceramic simple synthesis. ${ }^{35,61-63}$ Nowadays, Srinet and coauthors ${ }^{29}$ employed a thermal decomposition method increasing the Ba solubility to $5 \% \mathrm{~mol}$ at $\mathrm{ZnO}$ structure in accordance with theoretical results presented on Table, which indicate that the Ba-doped models from low amount, $6.25 \%, 12.5 \%$ and $25 \%$, show negative values for $\Delta \Delta \mathrm{G}$ and are stables at room temperature. Thus, the Ba solubility limit can be estimate as $25 \%$ in relation to $\mathrm{Zn}$ amount from modern experimental techniques. For $37.5 \%, 50 \%$ and $62.5 \%$ doping, we propose that these structures are unstable at room conditions due to a spinodal behavior, which is a region of phase diagram where simple oxides are more stables than solid solution. ${ }^{65}$ Examples for spinodal behavior in solid solutions are $\mathrm{TiO}_{2}-\mathrm{SnO}_{2}{ }^{66-68} \mathrm{TiO}_{2}-\mathrm{VO}_{2}{ }^{69}$ and $\mathrm{ZnO}-\mathrm{CdO}^{70}$ compounds.

Table 4. Theoretical values for mixing Gibbs Free Energy $\left(\Delta \mathrm{G}_{\text {mix }}\right)$ and Gibbs Free Energy in relation to $\mathrm{ZnO}(\Delta \Delta \mathrm{G})$ for $\mathrm{Ba}: \mathrm{ZnO}$ materials

\begin{tabular}{ccc}
\hline Model $(\%)$ & $\Delta \mathrm{G}_{\text {mix }}\left(\mathrm{kJ} \mathrm{mol}^{-1}\right)$ & $\Delta \Delta \mathrm{G}\left(\mathrm{kJ} \mathrm{mol}^{-1}\right)$ \\
\hline 0.0 & 0 & 0 \\
12.5 & -14.7944 & -1.3374 \\
25.0 & -22.2643 & -8.8117 \\
37.5 & -9.3082 & 4.1444 \\
50.0 & -13.1939 & 0.2587 \\
62.5 & -13.9751 & 0.5225 \\
75.0 & -7.6333 & -5.8193 \\
87.5 & -19.6976 & -6.2450 \\
100 & 0 & -13.4526 \\
\hline
\end{tabular}

\section{CONCLUSION}

We used DFT with periodic model to discuss structure, electronic, optical and ferroelectric properties available for Ba doping in $\mathrm{ZnO}$. Electronic and optical properties showed that Ba-doping from $6.12 \%$ to $37.5 \%$ are potential alternatives to be employed in electronic and optical devices, once the band-gap decrease changes 
the profile wavelength to the visible range. For $\mathrm{Ba}$-doped model at $50 \%$ was calculated a band-gap very close to pure $\mathrm{ZnO}$; while the Ba-doped models above $62.5 \%$ have insulating character. The band-gap variation is caused by $\mathrm{Ba}$ atoms influencing as Valence Band as Conduction Band. The ferroelectric property was evaluated for all models and presented Ba-doping as a good alternative to improve the ferroelectric properties of $\mathrm{ZnO}$ materials. However, the thermodynamic stability indicates that Ba solubility in $\mathrm{ZnO}$-wurtzite structure is limited at $25 \%$ regarding to $\mathrm{Zn}$ position in unit cell. Thus, the $\mathrm{Ba}: \mathrm{ZnO}$ models below $25 \%$ can be obtained through experimental techniques. Therefore, the $\mathrm{Ba}$-doped $\mathrm{ZnO}$ materials have showed as potential alternatives to replace perovskite-type in ferroelectric devices employed in several electronic and optical devices, solar cells, and photocatalytic processes.

\section{ACKNOWLEDGMENTS}

The authors acknowledge support from CNPq, CAPES and Fundação Araucária.

\section{SUPPLEMENTARY MATERIAL}

The Tables $1 \mathrm{~S}$ and $2 \mathrm{~S}$ as well as the Projected Density of States (Figure 1S) and Band Structures (Figure 2S) are available at http:// www.quimicanova.sbq.org.br in PDF format with free access.

\section{REFERENCES}

1. Chew, Z. J.; Li, L.; Mater. Lett. 2013, 91, 298.

2. Xun, C.; Xiaomin, L.; Xiangdong, G.; Xinjun, L.; Chang, Y.; Rui, Y.; Ping, J.; J. Phys. D: Appl. Phys. 2011, 44, 255104.

3. Gupta, M. K.; Sinha, N.; Kumar, B.; J. Appl. Phys. 2012, 112, 014303.

4. Zhang, F.; Li, X.; Gao, X.; Wu, L.; Zhuge, F.; Wang, Q.; Liu, X.; Yang, R.; He, Y.; Solid State Commun. 2012, 152, 1630.

5. Nedic, S.; Tea Chun, Y.; Hong, W.-K.; Chu, D.; Welland, M.; Appl. Phys. Lett. 2014, 104, 033101.

6. Gupta, M. K.; Kumar, B.; J. Mater. Chem. 2011, 21, 14559.

7. Qiuhong, T.; Jinbin, W.; Xiangli, Z.; Yichun, Z.; Qianjin, W.; Yi, Z.; Zhang, X.;Huang, S.; IEEE Trans. Electron Devices 2011, 58, 2738.

8. Sohn, J. I.; Choi, S. S.; Morris, S. M.; Bendall, J. S.; Coles, H. J.; Hong, W.-K.; Jo, G.; Lee, T.; Welland, M. E.; Nano Lett. 2010, 10, 4316.

9. Lee, S.; Kim, H.; Yun, D.-J.; Rhee, S.-W.; Yong, K.; Appl. Phys. Lett. 2009, 95, 262113.

10. Lee, D. U.; Kim, E. K.; Cho, W.-J.; Kim, Y.-H.; Im, H.; Thin Solid Films 2012, 521, 98 .

11. Zhao, J.-W.; Liu, F.-J.; Huang, H.-Q.; Hu, Z.-F.; Zhang, X.-Q.; Chin. Phys. B 2012, 21, 065201

12. Kang, Y. H.; Choi, J.-H.; Lee, T. I.; Lee, W.; Myoung, J.-M.; Solid State Commun. 2011, 151, 1739.

13. Wang, W.; Zhao, Q.; Xu, J.; Yu, D.; CrystEngComm 2012, 14, 3015.

14. Cho, S.; Kim, S.; Oh, E.; Jung, S.-H.; Lee, K.-H.; CrystEngComm 2009, $11,1650$.

15. Chen, P.; Gu, L.; Cao, X.; CrystEngComm 2010, 12, 3950.

16. Yang, Y.; Qi, J.; Guo, W.; Liao, Q.; Zhang, Y.; CrystEngComm 2010, 12, 2005.

17. Brillson, L. J.; Lu, Y.; J. Appl. Phys. 2011, 109, 121301.

18. Lee, Y.; Lee, S.; Ryu, H. T.; Kim, D. Y.; AIP Conf. Proc. 2011, 1399, 163.

19. Glinchuk, M. D.; Kirichenko, E. V.; Stephanovich, V. A.; Zaulychny, B. Y.; J. Appl. Phys. 2009, 105, 104101.

20. Lee, Y.; Kim, D.; Lee, S.; Fu, D.; J. Korean Phys. Soc. 2012, 60, 1891.

21. Dhananjay, Nagaraju, J.; Krupanidhi, S. B.; J. Appl. Phys. 2007, 101, 104104.
22. Singh, D. P.; Gupta, S. K.; Srivastava, A.; Manohar, R.; J. Lumin. 2013, 139,60 .

23. Özgür, Ü.; Hofstetter, D.; Morkoc, H.; Proc. IEEE 2010, 98, 1255.

24. Özgür, Ü.; Alivov, Y. I.; Liu, C.; Teke, A.; Reshchikov, M. A.; Doğan, S.; Avrutin, V.; Cho, S.-J.; Morkoç, H.; J. Appl. Phys. 2005, 98, 041301.

25. Klingshirn, C.; ChemPhysChem 2007, 8, 782.

26. Shen, X.; Sun, J.; Zhu, G.; Ji, Z.; Chen, Z.; Li, N.; J. Mater. Sci. 2013, 48, 2358.

27. West, A. R.; Basic solid state chemistry, $2^{\text {th }}$ ed., John Wiley \& Sons: Chichester, 2006.

28. Marana, N. L.; Sambrano, J. R.; de Souza, A. R.; Quim. Nova 2010, 33, 810 .

29. Srinet, G.; Kumar, R.; Sajal, V.; Mater. Lett. 2014, 126, 274.

30. Lee, S.; Lee, Y.; Young Kim, D.; Won Kang, T.; J. Appl. Phys. 2013, 114, 064102.

31. Schubert, M.; Ashkenov, N.; Hofmann, T.; Lorenz, M.; Hochmuth, H.; v. Wenckstern, H.; Grundmann, M.; Wagner, G.; Ann. Phys. 2004, 13, 61.

32. Voora, V. M.; Hofmann, T.; Schubert, M.; Brandt, M.; Lorenz, M.; Grundmann, M.; Ashkenov, N.; Schubert, M.; Appl. Phys. Lett. 2009, 94, 142904.

33. Voora, V. M.; Hofmann, T.; Brandt, M.; Lorenz, M.; Ashkenov, N.; Grundmann, M.; Schubert, M.; Appl. Phys. Lett. 2009, 95, 082902.

34. Böntgen, T.; Schöche, S.; Schmidt-Grund, R.; Sturm, C.; Brandt, M.; Hochmuth, H.; Lorenz, M.; Grundmann, M.; Thin Solid Films 2011, 519,2933

35. Fan, J.;Freer, R.; J. Mater. Sci. 1997, 32, 415.

36. Jindal, K.; Tomar, M.; Katiyar, R. S.; Gupta, V.; J. Appl. Phys. 2012, 111,102805 .

37. Sun, J.; Bian, J.; Wang, Y.; Zhang, S.; Wang, Y.; Feng, Q.; Liang, H.; Du, G.; Thin Solid Films 2012, 521, 253.

38. Dutta, R.; Mandal, N.; Appl. Phys. Lett. 2012, 101, 042106.

39. Bantounas, I.; Goumri-Said, S.; Benali Kanoun, M.; Manchon, A.; Roqan, I.; Schwingenschlögl, U.; J. Appl. Phys. 2011, 109, 083929.

40. Otal, E. H.; Yoon, S.; Aguirre, M.;Weidenkaff, A.; J. Alloys Compd. 2011, 509, Supplement 1, S364.

41. Hwan Ko, Y.; Hyun Lee, S.; Su Yu, J.; Appl. Phys. Lett. 2013, 103, 022911.

42. Yang, Y. C.; Song, C.; Wang, X. H.; Zeng, F.; Pan, F.; Appl. Phys. Lett. 2008, 92, 012907.

43. Heo, S.; Sharma, S. K.; Lee, S.; Lee, Y.; Kim, C.; Lee, B.; Lee, H.; Kim, D. Y.; Thin Solid Films 2014, 558, 27.

44. Peintinger, M. F.; Oliveira, D. V.; Bredow, T.; J. Comput. Chem. 2013, 34,451 .

45. Zagorac, D.; Doll, K.; Schön, J. C.; Jansen, M.; Chem. - Eur. J. 2012, $18,10929$.

46. Hay, P. J.;Wadt, W. R.; J. Chem. Phys. 1985, 82, 299.

47. Stephens, P. J.; Devlin, F. J.; Chabalowski, C. F.; Frisch, M. J.; J. Phys. Chem. 1994, 98, 11623.

48. Becke, A. D.; J. Chem. Phys. 1993, 98, 5648.

49. Becke, A. D.; Phys. Rev. A 1988, 38, 3098.

50. Lee, C.; Yang, W.; Parr, R. G.; Phys. Rev. B 1988, 37, 785.

51. Monkhorst, H. J.; Pack, J. D.; Phys. Rev. B 1976, 13, 5188

52. Pisani, C.; Dovesi, R.; Roetti, C.; Hartree-Fock ab initio Treatment of Crystalline Systems.; Springer Berlin Heidelberg: 1988.

53. Dovesi, R.; Orlando, R.; Civalleri, B.; Roetti, C.; Saunders, V. R.; Zicovich-Wilson, C.-M.; Zeitschrift für Kristallographie 2005, 220, 571.

54. Dovesi, R.; Saunders, V. R.; Roetti, C.; Orlando, R.; Zicovich-Wilson, C. M.; Pascale, F.; Civalleri, B.; Doll, K.; Harrison, N. M.; Bush, I. J.; D'Arco, P.; Llunell, M.; CRYSTALO9 User's Manual, University of Torino: Torino, 2009

55. Kokalj, A.; J. Mol. Graphics Modell. 1999, 17, 176.

56. Kokalj, A.; Comput. Mater. Sci. 2003, 28, 155.

57. Denton, A. R.; Ashcroft, N. W.; Phys. Rev. A 1991, 43, 3161. 
58. Vegard, L.; Z. Physik 1921, 5, 17.

59. Smart, L. E.; Solid state chemistry: an introduction, $3^{\text {th }}$ ed., Taylor \& Francis: Boca Raton, 2005.

60. Kwok, H. L.; Electronic Materials, PWS Publishing Company: Boston, 1997.

61. Uematsu, K.; Morimoto, T.; Kato, Z.; Uchida, N.; Sa'to, K.; J. Mater. Sci. Lett. 1987, 6, 1285

62. Ghashang, M.; Rajabi, A. R.; Jabbarzare, S.; Shafiee, M. R. M.; Curr. Nanosci. 2014, 10, 312.

63. Water, W.; Fang, T.-H.; Ji, L.-W.; Meen, T.-H.; Yan, Y.-S.; Journal of Science and Innovation 2011, 1, 25

64. Lare, Y.; N'Konou, K.; Haris, M.; Baneto, M.; Amou, K. A.; Napo, K.; Adv. Mater. 2014, 3, 63 .
65. Zakrzewska, K.; Thin Solid Films 2001, 391, 229.

66. Padurow, N. N.; Naturwissenschaften 1956, 395

67. Sensato, F. R.; Custodio, R.; Longo, E.; Beltrán, A.; Andrés, J.; Catal. Today 2003, 85, 145 .

68. Cassia-Santos, M. R.; Souza, A. G.; Soledade, L. E. B.; Varela, J. A.; Longo, E.; J. Therm. Anal. Calorim. 2005, 79, 415.

69. Hiroi, Z.; Yoshida, T.; Yamaura, J.; Okamoto, Y.; APL Mater. 2015, 3, 062508.

70. Lashkarev, G. V.; Shtepliuk, I. I.; Ievtushenko, A. I.; Khyzhun, O. Y.; Kartuzov, V. V.; Ovsiannikova, L. I.; Karpyna, V. A.; Myroniuk, D. V.; Khomyak, V. V.; Tkach, V. N.; Timofeeva, I. I.; Popovich, V. I.; Dranchuk, N. V.; Khranovskyy, V. D.; Demydiuk, P. V.; Low Temp. Phys. 2015, 41, 129. 